\title{
各種肥料がミジンコの繁殖に及洔す 影響に就ての實驗一IV
}

\author{
藤 田贸 吉 \\ (静岡大学教育学部) \\ Experiments on the Effects of Varicus Kinds and Combinations of \\ Chemical Fertilizers on the Reproduction of Daphnia longispina- $\mathrm{N}$ \\ Scukiti Huzita
}

\begin{abstract}
The experiments on the effect of the chemical fertilizers added before and after the administration of the organic ones to the rate of reproduction of Daphnia longispina was carried out. In case of using the fish meal as the organic fertilizer, no remarkable effect by the addition of the chemical ore was seen. But, in case of using the rice bran as the organic fertilizer, the effect of the chemical one added at 3 rd day since the supply of water could be recogrized and esfecially the ammonium sulphate as the chemical ore produced the good reproduction of this species (Tables 2 \& 3 ).

Moneover, Daphnia to which the rice brar, as tha orga ic fertilizer was giver became red and this phenomeror was considered to ke caused by their livirig food.
\end{abstract}

緒言

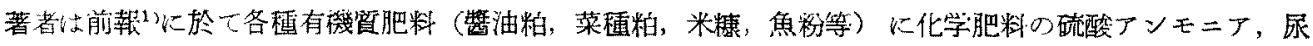

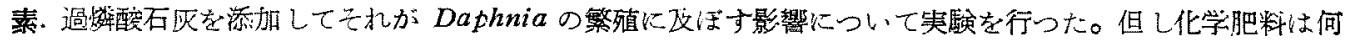

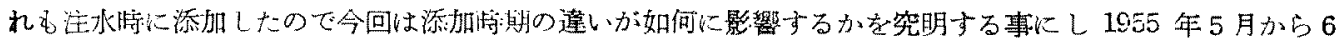
月にかけて筷験を行つたので報告する。

\section{実 驗 方 法}

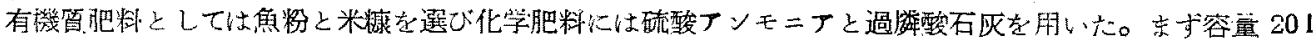

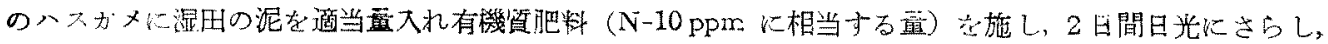

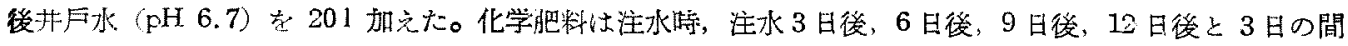

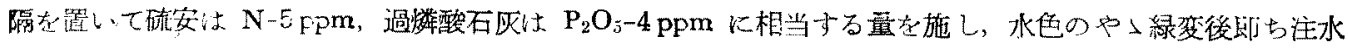

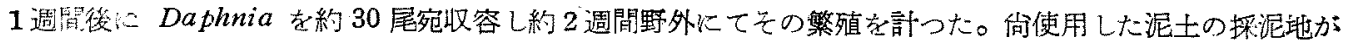

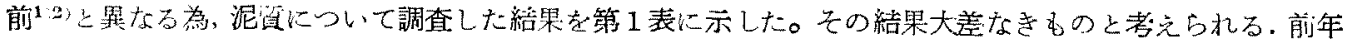

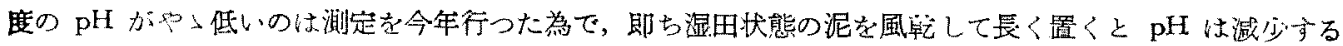
傾向放る。

\section{結 果及ひ考 察}

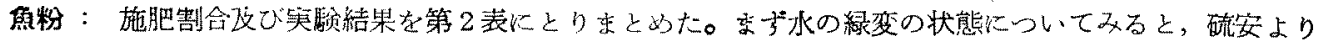

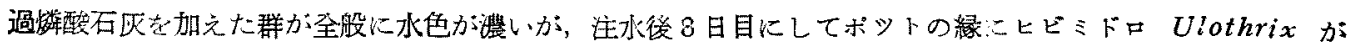

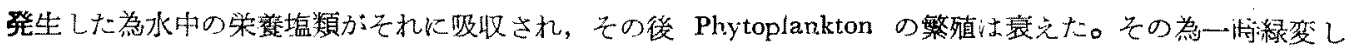

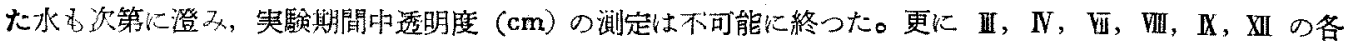


Table 1. Results of the selection aralysis, $\mathrm{pH}$ and loss by ignition of mud used in the experiments (195:, 1955)

\begin{tabular}{|c|c|c|c|c|c|c|c|c|c|}
\hline & \multicolumn{6}{|c|}{ Diaineter of muds grain (m. m..) } & \multirow{2}{*}{$\mathrm{pH}$} & \multirow{2}{*}{$\begin{array}{r}\text { Loss by } \\
\text { ignition } \\
\%\end{array}$} & \multirow{2}{*}{$\begin{array}{l}\text { Place of } \\
\text { sampling }\end{array}$} \\
\hline & $3.00<$ & $3.00 \sim 1.00$ & $1.00 \sim 0.50$ & $0.50 \sim 0.20$ & $0.20 \sim 0.05$ & $0.05>$ & & & \\
\hline $\begin{array}{l}\text { Present } \\
\text { experiment } \\
\text { Past }\end{array}$ & 2.0 & 7.0 & 10.4 & 28.5 & 19.7 & 32.4 & 6.3 & 7.15 & Sizuoka \\
\hline expcrimert & 1.1 & 15.3 & 14.5 & 18.7 & 14,0 & 36.4 & 6.1 & 692 & Simada \\
\hline
\end{tabular}

Tatle 2. Variation of $\mathrm{pH}$ and quartity rcproduced of "Daphnia longispina in pots,

\begin{tabular}{|c|c|c|c|c|c|c|c|c|}
\hline \multirow{2}{*}{$\begin{array}{l}\text { No. of } \\
\text { pots }\end{array}$} & \multirow{2}{*}{$\begin{array}{l}\text { Combiratior; } \\
\text { of fertilizers }\end{array}$} & \multirow{2}{*}{$\begin{array}{l}\text { Addition time } \\
\text { of chemical } \\
\text { fertulizers }\end{array}$} & \multicolumn{5}{|c|}{ pH of water * } & \multirow{2}{*}{$\begin{array}{l}\text { Revroduct-*1 } \\
\text { ion of } \\
\text { Daphnia }\end{array}$} \\
\hline & & & $\begin{array}{l}\text { after } \\
4 \text { days }\end{array}$ & 10 & 16 & 22 & $\begin{array}{l}\text { avera- } \\
\text { ge }\end{array}$ & \\
\hline I & Cortrol (no fertilizer) & & 7.1 & 9.3 & 9.2 & 8.8 & 8.6 & $0.8 \mathrm{cc}$ \\
\hline $\mathbb{I}$ & Fish meal $0.09 \mathrm{~g} . / 1$. & & 7.0 & 9.3 & 9.2 & 9.3 & 8.7 & 2.2 \\
\hline III & \multirow{6}{*}{$\begin{array}{l}\text { Fish meal } 0.09 \mathrm{~g} . / 1 \\
+ \text { Ammonium sul. } \\
\text { phate } 0.025 \mathrm{~g} . / 1\end{array}$} & time of pouring water & 7.0 & 9.3 & 9.3 & 9.4 & 8.8 & 0.3 \\
\hline $\mathbf{N}$ & & 3 days & 7.1 & 9.3 & 9.3 & 9.3 & E. 8 & 0.6 \\
\hline $\mathbf{V}$ & & 6 days & 7,0 & 9.2 & 9.1 & 9.1 & \&. 6 & 1.6 \\
\hline $\mathrm{V}$ & & 9 days & 7.0 & 9.1 & 9.3 & 9.4 & 8.7 & 0.8 \\
\hline VII & & 12 days & 7.0 & 9.3 & 9.3 & 9.4 & $\varepsilon . \varepsilon$ & 0.4 \\
\hline Vill & & time of pouring waser & 7.1 & 9.3 & 9.3 & 9.3 & 8.8 & 0.2 \\
\hline $\mathbf{X}$ & \multirow{4}{*}{$\begin{array}{l}\text { Fish meal } 0.09 \mathrm{~g} . / 1 \\
+ \text { Calcium superph- } \\
\text { osphate } 0.025 \mathrm{~g} . / 1\end{array}$} & 3 days & 7.0 & 9.3 & 9.4 & 9.3 & $\varepsilon . \varepsilon$ & 0 \\
\hline $\mathrm{X}$ & & 6 days & 7.1 & 9.3 & 9.3 & 9.3 & 8.8 & 0.5 \\
\hline XI & & 9 days & 7.1 & 9.3 & 9.3 & 9.3 & 8.8 & 0.4 \\
\hline XII & & 12 days & 7.0 & 9.3 & 9.3 & 9.0 & 8.7 & 0.3 \\
\hline
\end{tabular}

* Value of at $10 \mathrm{a}, \mathrm{m}$.

* Precifitating quartity of Daphnia in water of 201 . (after $14 \mathrm{da} / \mathrm{s}$ )

W. T. ranged fre $18.2 \mathrm{C}$. to $28.9^{\circ} \mathrm{C}$, and the mear, of the average temerature at $10 \mathrm{a}, \mathrm{m}$. and 2 p.m. was $24.5^{\circ} \mathrm{C}$.

ポットにはアミミドロ Hydrodict yon reticulatum b発生した。然し魚粉の东の而上, 注水6日後に化

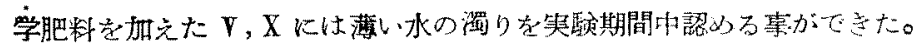

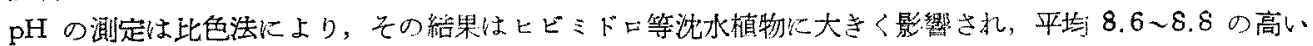

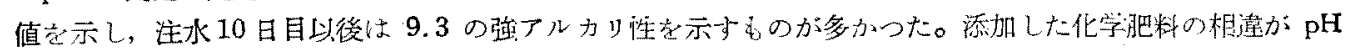

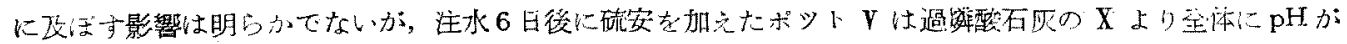
低く，このポットに氷の濁りが最も多く管察された。

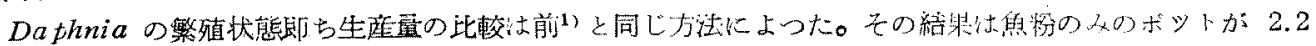

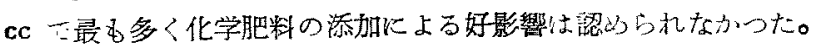

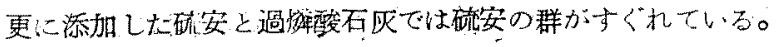

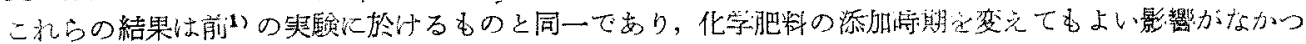

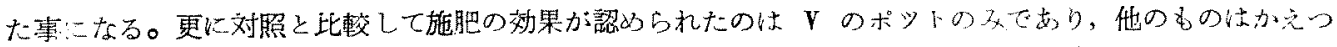

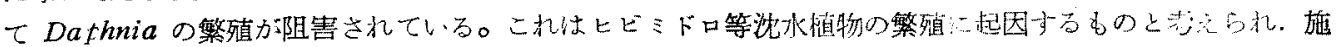

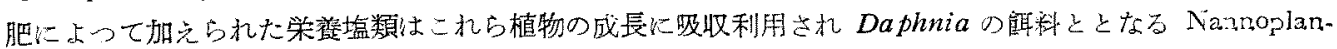

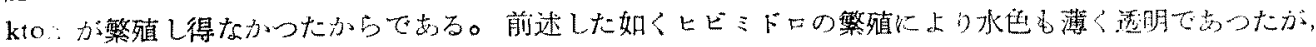

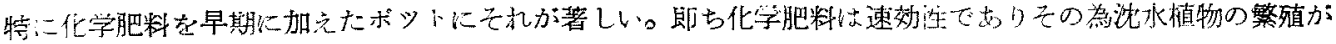

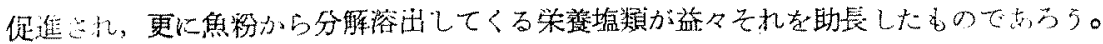

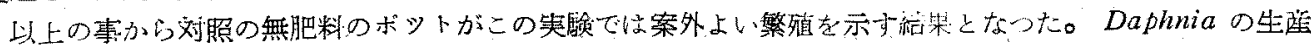

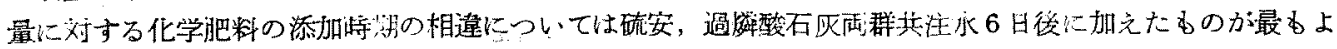




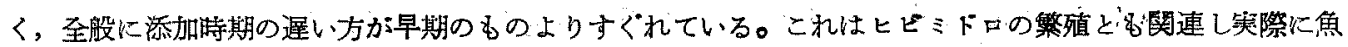
粉の分解の状態を知らなければその理由は明らかにする事ができないが，最す繁殖のすぐれていた注水6日

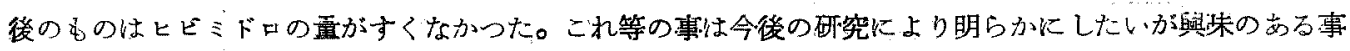
唡と思う。

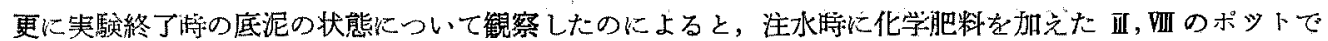
は底泥の一部が墨色化していた。これは魚粉と硫安及文び過燐酸石灰の間に於ける化学反応の䋨果と思放れる

Table 3. Variation of $\mathrm{pH}$ and quantity reproduced of Daphnia longispina in pots.

\begin{tabular}{|c|c|c|c|c|c|c|c|c|}
\hline \multirow{2}{*}{$\begin{array}{l}\text { No. of } \\
\text { pots }\end{array}$} & \multirow{2}{*}{$\begin{array}{l}\text { Combiration } \\
\text { of fertilizers }\end{array}$} & \multirow{2}{*}{\multicolumn{2}{|c|}{$\begin{array}{l}\text { Addition time } \\
\text { of chemical } \\
\text { fertilizers }\end{array}$}} & \multicolumn{4}{|c|}{ pH of water $*$} & \multirow{2}{*}{$\begin{array}{l}\text { Reproduction *** } \\
\text { of Daphnia }\end{array}$} \\
\hline & & & & $\begin{array}{l}\text { after } \\
4 \text { days }\end{array}$ & 10 & 16 & average & \\
\hline I & Cor:trol (no fertilizer) & \multirow{3}{*}{\multicolumn{2}{|c|}{ time of pouring water }} & 7.2 & 9.1 & 7.0 & 7.8 & $2.2 \mathrm{cc}$ \\
\hline II & Rice bran $0.5 \mathrm{~g} . / \mathrm{I}$. & & & 6.7 & 7.2 & 8.7 . & 7.5 & 5.8 \\
\hline III & \multirow{5}{*}{$\begin{array}{l}\text { Rice bran } 0.5 \mathrm{~g} . / 1 .+ \\
\text { Ammonium sulphate } \\
0.025 \mathrm{~g} . / 1 .\end{array}$} & & & 6.7 & 9.1 & 7.6 & 7.8 & 4.0 \\
\hline IV & & \multirow[t]{3}{*}{ after } & 3 days & 6.7 & 9.3 & 7.0 & 7.7 & 12.4 \\
\hline $\mathbf{r}$ & & & 6 days & 6.7 & 9.1 & 7.7 & 7.8 & 3.0 \\
\hline VI & & & 9 days & 6.7 & 7.9 & 7.0 & 7.3 & 4.6 \\
\hline VII & & & 12 days & 6.7 & 7.5 & 8.3 & 7.5 & 5.4 \\
\hline VIII & & \multicolumn{2}{|c|}{ time of pouring water } & 6.7 & 9.2 & 8.9 & 8.3 & 4.0 \\
\hline $\mathbf{X}$ & & after & 3 days & 6.7 & 7.7 & 7.1 & 7.2 & 9.4 \\
\hline $\mathrm{X}$ & \multirow{3}{*}{$\begin{array}{l}\text { Rice brar } 0.5 \mathrm{~g} . / 1 .+ \\
\text { Calcium superphos- } \\
\text { phate } 0.025 \mathrm{~g} . / 1 .\end{array}$} & & 6 days & 6.7 & 8.8 & 7.5 & 7.7 & 5.0 \\
\hline XI & & & 9 days & 6.7 & 8.5 & 6.9 & 7.4 & 6.0 \\
\hline XII & & & 12days & 6.7 & 9.0 & 7.0 & 7.6 & 3.8 \\
\hline
\end{tabular}

* Value of at $10 \mathrm{a} . \mathrm{m}$.

** Precipitating quantity of Daphnia in water of 201 . (after 14 days)

W. T ranged from $19.6^{\circ} \mathrm{C}$. to $35.0^{\circ} \mathrm{C}$. and the mean of the average lemperature at $10 \mathrm{a}, \mathrm{m}$. and 2 p.m. was $27.4^{\circ} \mathrm{C}$.
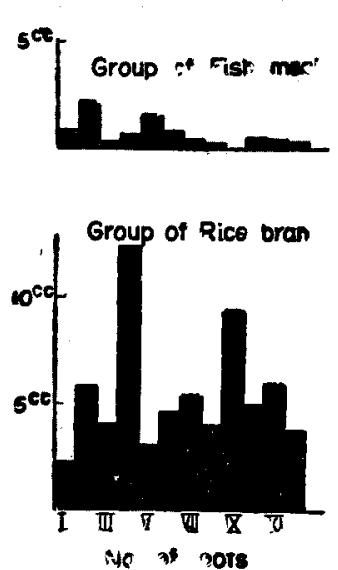

Fig. 1. Precipitatirg quartity of Daphnia obtained by the experimerts that Chemical fertilizers are added to Organic fertilizers by changing time

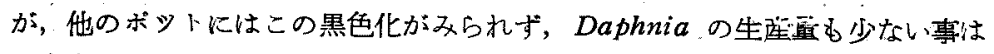

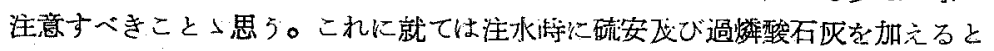

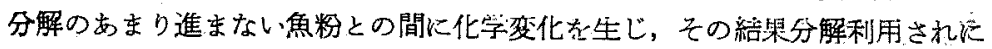
くい型に変わるのではないだろらか。これがヒビミドロの繁殖とも関墥して化 学肥料の添加時期の違いが肥効飞影響する樣考えられる。

更に II， N, V, XII のボットには Chironomus larva が棲息していた。

米棣：施肥割合更び実験結果を第 3 表に示す。注水（6月6日）後の緑変 の状態は魚粉の群とは異なり磞安を添加したポツトが全床に濃い。即ち最む水

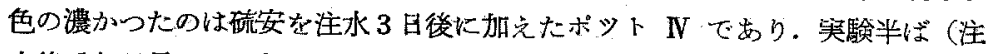
水後 14 日目から 18 日目迄）加ら，17.0 20.0 cm の透明度を毎巨観測し得 た。合その水を検鏡した結果は殆んどSelenastrum sp。であうた。

これに対し過燐酸石灭を加えたポットですやけり注水 3 日後の・X が水色港 く, 14 日目に $24.0 \mathrm{~cm}$ の透明度を測定したが, その後はや〉裉色した。斯ち 透明度を測定し得たのは $\mathbf{N} と \mathbf{X}$ のつのポットのみであり，他のものは濁り は認める事ができたが全般に水色は薄い。然し硫安を加えたV，湴と米棣の及 の II のポツトでは実験期間相当濃い白濁を観察した。

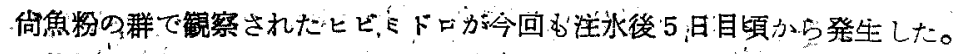

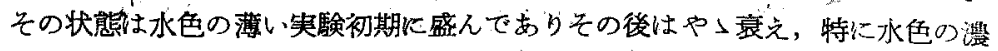
かつたポット $\mathbf{N}$ ではビミドロの発生が多かつたが, 緑変の進行につれ光の 
不足加ら枯死した。

$\mathrm{pH}$ の変化は始めは米糠の分解による有機酸の為に6.7の弱酸性であつたがヒビミドロや Phytoplar:kton

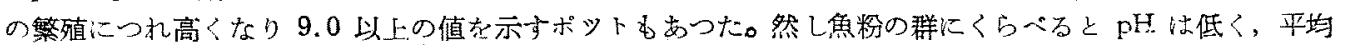
7.2 8.3 でポット Vill 赵余き全部 8.0 以下の值である。向 $\mathrm{max}$. は注水後 10 日目に多く泰われている む゙添加した硫安と過燐酸石灰の間には明らかな美は認められない。

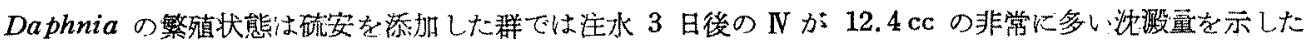

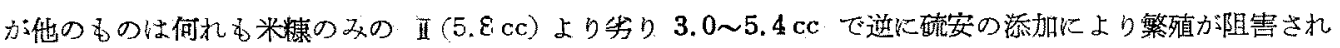

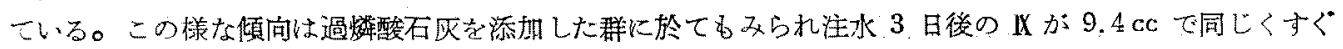
れているが他のボットでは 3.8〜6.0 cG である。この結果を前りの钮験と比較すると大分異なつている。即

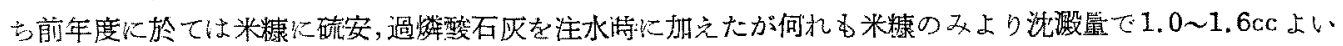
整殖を示していた。その原因行就てまず天候条件を比較してみると平均水温では今年は前年股より $1.52 \mathrm{C}$ 高々, 睛天日6 6 日間（前年度は 3 日間）をかぞえ, その結果肥料の分解, Phytoplanktor，の繁殖には好影

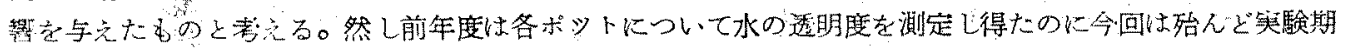

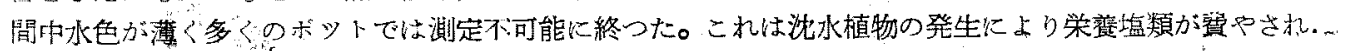
Phytopla :kton の繁殖が扸制されたすのと考光る。即ち化学肥料の添加により沈水植物の成長が盛々助長さ え， その為米棣のみのボットの方がすぐれた結果となつた。たが注水 3 日後に化学肥料を加えたポシトでは Daphnia の非常によい䈯をみたが，これは添加诗期が適当であり Phytoplankton の繁殖がよく，從つて

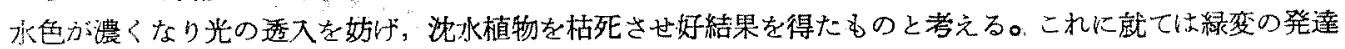
につれたビミドロが枯死した事からも以上の推察は正しいものと思う。從つて沈水植物が発生した特の化学 肥精の添加山注意を要し，今回の笑験では注水 3 日後が添加時期としてすぐれているが，これを最適時期と

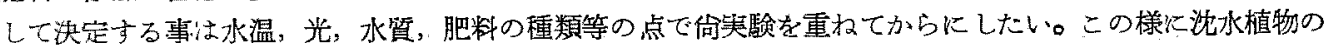
抑制は化学肥料の添加時期を適当にすることで目的を迋成できるが，時期を誤ると逆の結果を招くから，む

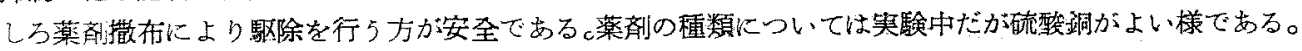

以上述べた如く沈水植物は Phytoplar,ktor の繁殖に悪影響を与之るが，これに就ては松江(1947)，中村中 六 (1948), 中柯一雄(1950), MATIDA (1953), 中村一雄, 外(1954), MATIDA (1955) 等の多くの人に上り

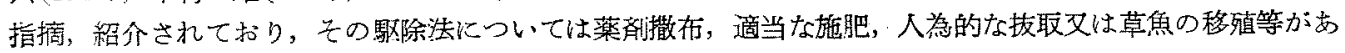
けられている。而してミジンコ繁殖の目的の為には前にる述べた如く薬刘による方法が操作が簡便であり， しかも枯死した植物か涹敗分解してミジンコの繁殖に好影響を与えるから適当と考它る。この詳細に就ては 別に報告するが中村一雄，外 (1954)，MATIDA（1955）等む溜池で同じ様な現象を観察している。

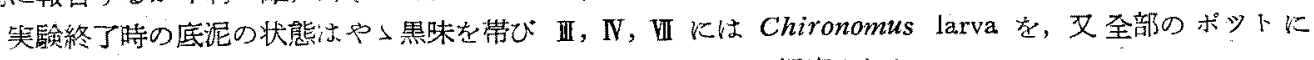
Culex larva が，劣ヒビミドロは I，II，III 苯除いたポツトに観察された。

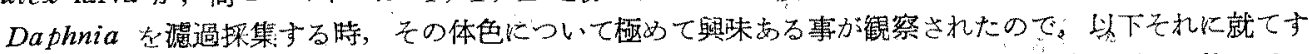
こし述へてみたい。それは最も繁殖のすぐれていたボットINのDaphnia は綺麗な赤色を呈し，他のポッ

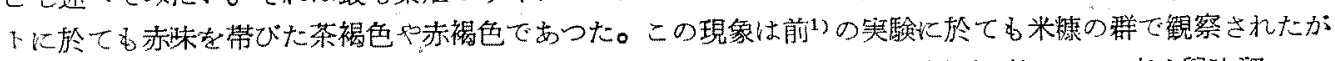

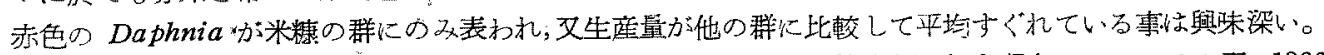

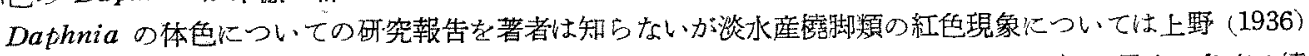

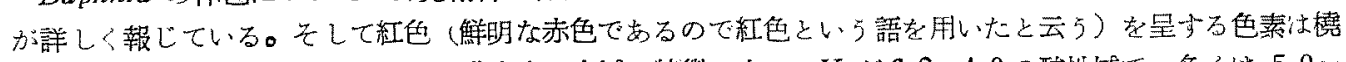

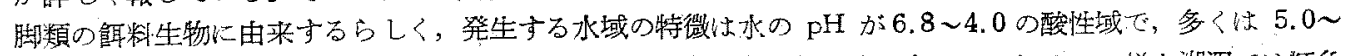

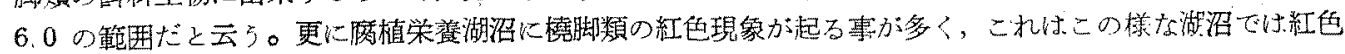
素を生じや政、徽生物に富んでいるからだと云う。

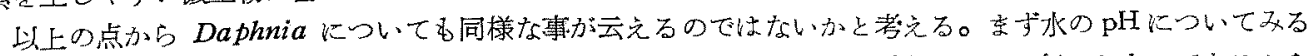
と，他の肥料に比へて来粶を施したポットは低く，この $\mathrm{pH}$ の澌定は表面水について行つたあので责るから

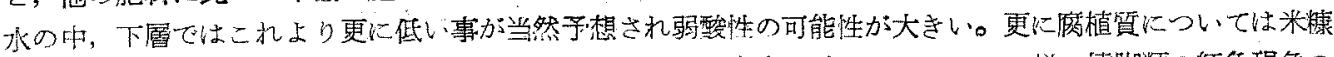

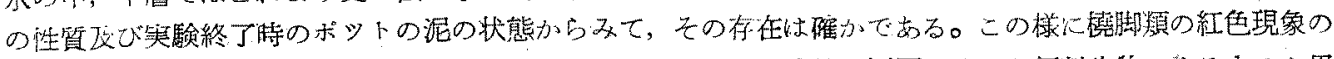

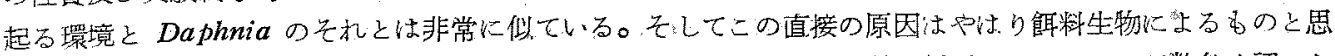

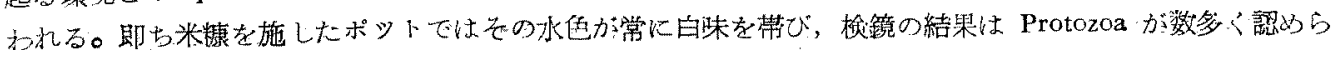




\section{$11 \div 2$}

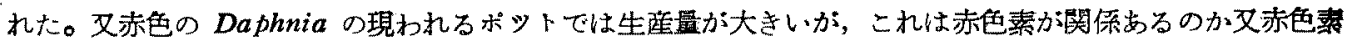
を持つ慨料生物に起因するのか不明だが，何かの機会に究明したいと考えている。

\section{摘要}

1）魚粉改び米棣に化学肥料（硫安，過嫾酸石友）を特期を变えて添加し，それが Daphnta の繁殖に及

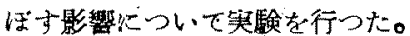

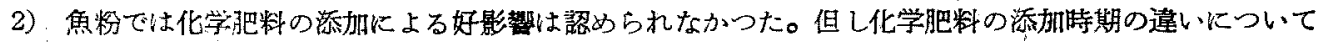
は注水6日後に加竟たるのか硫安，過燐踆石灰とるDaphnia の繁殖はすぐれていた。

3) 米精では注水 3 日後に化学肥料を加光たるのが非常に繁殖がよく, 硫安は過燐酸石灰よりすぐれてい to

4) 米䗧の淎でDaphnia の紅色現象が観察された。

\section{女献}

1）藤田恩吉： 静岡大学数育学部研究報告, $5,174 \sim 182$ (1954).

2) 同上：日水会誌，20，965 968 (1955).

3）同上：日水会誌，20,873 877 (1955).

4) 松江吉行： 農学, Vol. 1, No. 7 (1947).

5）中朴中六：“譨村盖魚の実際” 倚学社, 東京, (1943), pp. 92 96.

6) 中村一雄：日水会誌，16，127１31 (1950).

7) Matida, Y : Bull. Freshwater Fish. Res. Lab., Vol. 2, No. 1 (1953).

8) 中村一雄, 島立孫亥, 小山 一, 大久保英次： 淡水区水壁研究所報告， 3，1，(1954):

9) Matida, X: Bull. Freshwater Fish. Res. Lab., Vol. 4, No. 1 (1955).

10）上野益三：植物及動物，4，1181 1192 (1936). 